\title{
АНАЛИЗ СТРУКТУРЫ СТРОИТЕЛЬНОЙ ОТРАСЛИ В КОНТЕКСТЕ ВЛИЯНИЯ ИНФОРМАЦИОННОЙ СРЕДЫ НА ПОЗИЦИОНИРОВАНИЕ БРЕНДА ЗАСТРОЙЩИКА НА РЫНКЕ
}

\author{
(C) 2021 Конников Евгений Александрович
}

кандидат экономических наук, доцент, Высшая инженерно-экономическая школа Санкт-Петербургский политехнический университет Петра Великого, Россия, Санкт-Петербург E-mail: konnikov.evgeniy@gmail.com

(C) 2021 Чорная Софья Александровна

Высшая инженерно-экономическая школа

Санкт-Петербургский политехнический университет Петра Великого, Россия, Санкт-Петербург E-mail: sonya.chornaya@mail.ru

Строительная отрасль является одной из наиболее уникальных, с точки зрения экономического взаимодействия производителей и потребителей блага. Данный факт в первую очередь обусловлен уникальной ценностной спецификой объектов строительства. Данная специфика определяет значимость подготовительного этапа потребления, в первую очередь подразумевающего исследование рынка. Следовательно, эффективное многомерное представление строительной компании в информационной среде определяет результативность ее деятельности. В рамках данной статьи представлены результаты комплексного анализа структуры строительной отрасли в контексте влияния информационной среды на позиционирование бренда застройщика на рынке.

Ключевые слова: строительная компания, информационная среда, тональность, внешняя среда.

Строительная отрасль отличается наличием определенного уровня консервативности. До недавнего времени ключевыми факторами макросреды, оказывающими воздействие на деятельность и финансовый результат строительных компаний, выступали цены на строительные материалы (в т.ч. и на естественные монополии), динамика процентной ставки по кредитам, нормативно-правовое регулирование деятельности строительных компаний и безусловно уровень конкуренции в отрасли. Но с развитием цифровых технологий и распространением разного рода цифровых маркетинговых механизмов, значимость такого фактора, как «репутация застройщика» выросла в несколько раз. Потребитель стал более ответственно подходить к приобретению жилья, что выражается в проведении предварительного анализа рынка недвижимости, выставляемой на продажу, и застройщиков в рамках конкретного субъекта Российской Федерации. В связи с этим имеют место такие факторы цифровой (диджитал) среды, как «количество запросов» в поисковых системаx Google и Яндекс и состояние тональности информационного фона вокруг наименования бренда застройщика. Таким образом, при реализации анализа внешней среды компании- застройщика необходимо провести изучение воздействия двух групп факторов: объективных и информационных.

В рамках данного исследования производится определение конкурентных преимуществ и положения в строительной отрасли на примере строительной компании АО «Эталон ЛенСпецСМУ», являющейся Санкт-Петербургской дочерней компанией «ГК Эталон». Отметим также, что исследование проводилось для компаний, оперирующих в рамках г. Санкт-Петербурга и ЛО.

Для целей анализа был определен набор следующих факторов информационной среды: тональность информационной среды вокруг бренда застройщика и уровень заинтересованности целевой аудитории в конкретном застройщике. Фактор результативности строительных работ, выполняемых застройщиком, был определен к группе объективных факторов макросреды. И в качестве фактора, характеризующего состояние внутренней среды компаний, был использован Коэффициент рентабельности продаж.

Построение стратегии развития компании предполагает оценку и сравнение показателей анализируемой компании относительно ее конкурентов. В связи с этим возникает необходимость проведения анализа структуры строи- 
тельной отрасли, результаты которого позволят определить пул ключевых конкурентов АО «Эталон ЛенСпецСМУ» и оценить положение рассматриваемой компании в отрасли.

Проведем первичный анализ рынка застройщиков Санкт-Петербурга на основании данных специализированного портала «Единый ресурс застройщиков, с целью формирования выборки компаний-ключевых конкурентов анализируемого застройщика.

Рынок застройщиков Санкт-Петербурга носит вариативный характер. Ранжирование компаний может быть произведено по нескольким критериям: по объему текущего строительства, по объему ввода жилья в эксплуатацию, а также по потребительским качествам жилых комплексов. Ввиду фактора задержки сдачи объектов недвижимости, выражающемся в переносе сроков их окончательной сдачи и приемки, для целей данного исследования отрасли, при составлении собственного первичного рейтинга компанийзастройщиков Санкт-Петербурга, было принято решение в качестве приоритетного критерия использовать количество объектов, введенных в эксплуатацию на конец конкретного периода. Кроме того, в качестве аргумента в пользу использования данного критерия с целью ранжирования строительных компаний выступает специфика признания выручки строительных компаний: зачастую признание выручки происходит после заключения акта о передачи права собственности на объект недвижимости, а как известно, данный документ может быть подписан после того, как объект строительства полностью сдан (в т.ч. введен в эксплуатацию).

Изучение данных об объемах введенных в эксплуатацию объектов недвижимости компаний-застройщиков Санкт-Петербурга по состоянию на конец 2020 года позволило выделить шесть основных конкурентов рассматрива- емого предприятия: Холдинг Setl Group, Группа лСР, Группа ЦДС, Glorax Development, СК Дальпитерстрой и СПб Реновация (см. таблицу 1) [1].

Следующий этап анализа предполагает подробное рассмотрение конкурентов анализируемого предприятия и определение примерной рыночной позиции компании. Для наглядности анализа была составлена карта стратегических групп конкурентов АО «Эталон ЛенСпецСМУ» (см. рисунок 1 и 2).

Карта стратегических групп требует наличия данных по ряду показателей. В рамках данного анализа карта строилась по показателям выручки, коэффициента результативности работ и занимаемой доли на рынке на конец 2019 и 2020 года.

На основании найденных в открытом доступе данных составим рейтинг основных, действующих на рынке, компаний-застройщиков СанктПетербурга. Исследование будет проводиться на основании данных Единого ресурса застройщиков. На сайте ЕРЗ представлено несколько рейтингов застройщиков, в рамках данного анализа будут использованы рейтинг застройщиков г. Санкт-Петербург «по объему текущего строительства» и «по объему ввода жилья в эксплуатацию» на 01.01.2020 и 01.01.2021 [1].

Как было указано ранее, рынок застройщиков Санкт-Петербурга довольно разнообразен, по данным Единого Ресурса Застройщиков на нем задействовано более 90 компаний. В связи с этим будет логичным составить топ-7 основных игроков рынка строительства.

В качестве дополнения к данным официальных рейтингов был разработан коэффициент результативности строительных работ. Так, произведем расчет коэффициента результативности строительных работ для отобранных компаний за 2019 и 2020 гг. Полученные данные ранжирования за 2019 год отображены в таблице 2, а за 2020 год в таблице 3.

Таблица 1. Рейтинг застройщиков Санкт-Петербурга по объему введенных в эксплуатацию объектов за 2019 и 2020 гг.

\begin{tabular}{|c|l|l|l|l|}
\hline год & \multicolumn{2}{|c|}{2019} & \multicolumn{2}{c|}{2020} \\
\hline № & \multicolumn{1}{|c|}{ Застройщик } & \multicolumn{1}{c|}{ Введено, м3 } & \multicolumn{1}{c|}{ Застройщик } & 703052 \\
\hline 1 & Холдинг Setl Group & 524222 & Холдинг Setl Group & 361822 \\
\hline 2 & Группа ЛСР & 360266 & Группа ЛСР & 219176 \\
\hline 3 & СК Дальпитерстрой & 217379 & Группа Эталон & 200273 \\
\hline 4 & Группа Эталон & 142642 & Glorax Development & 187171 \\
\hline 5 & СПб Реновация & 114105 & Группа ЦДС & 177833 \\
\hline 6 & Glorax Development & 73130 & СПб Реновация & 59271 \\
\hline 7 & Группа ЦДС & 66602 & СК Дальпитерстрой & \\
\hline
\end{tabular}


Таблица 2. Рейтинг застройщиков Санкт-Петербурга за 2019 год

\begin{tabular}{|c|l|c|c|c|c|c|}
\hline № & \multicolumn{1}{|c|}{ Застройщик } & Строится, м2 & Введено, м3 & $\begin{array}{c}\text { Доля в регионе } \\
\text { на 2019 г }\end{array}$ & $\begin{array}{c}\text { Коэффициент } \\
\text { результатив- } \\
\text { ности работ }\end{array}$ & $\begin{array}{c}\text { Выручка, млн. } \\
\text { руб. }\end{array}$ \\
\hline 1 & Холдинг Setl Group & 2558202 & 524222 & $17 \%$ & 0,20 & 98091 \\
\hline 2 & Группа ЛСР & 2702256 & 360266 & $15 \%$ & 0,13 & 37613 \\
\hline 3 & СК Дальпитерстрой & 446434 & 217379 & $4 \%$ & 0,49 & 1991 \\
\hline 4 & Группа Эталон & 469913 & 142642 & $2 \%$ & 0,30 & 17182 \\
\hline 5 & СПб Реновация & 286222 & 114105 & $3 \%$ & 0,40 & 3512 \\
\hline 6 & Gloraх Dеvelopment & 269836 & 73130 & $3 \%$ & 0,27 & $\begin{array}{c}\text { Нет информа- } \\
\text { ции }\end{array}$ \\
\hline 7 & Группа ЦДС & 610923 & 66602 & $5 \%$ & 0,11 & 112811 \\
\hline
\end{tabular}

Таблица 3. Рейтинг застройщиков Санкт-Петербурга за 2020 год

\begin{tabular}{|c|l|c|c|c|c|c|}
\hline № & \multicolumn{1}{|c|}{ Застройщик } & Строится, м2 & Введено, м3 & $\begin{array}{c}\text { Доля в регио- } \\
\text { не на 2020 г }\end{array}$ & $\begin{array}{c}\text { Коэф. резуль- } \\
\text { тативности } \\
\text { работ }\end{array}$ & $\begin{array}{c}\text { Выручка, млн. } \\
\text { руб. }\end{array}$ \\
\hline 1 & Холдинг Setl Group & 2115024 & 703052 & $20 \%$ & 0,33 & 116505 \\
\hline 2 & Группа ЛСР & 2301874 & 361822 & $16 \%$ & 0,16 & 35892 \\
\hline 3 & Группа Эталон & 462563 & 219176 & $5 \%$ & 0,47 & 17118 \\
\hline 4 & Glorax Development & 69748 & 200273 & $3 \%$ & 2,87 & $\begin{array}{c}\text { Нет информа- } \\
\text { ции }\end{array}$ \\
\hline 5 & Группа ЦДС & 422695 & 187171 & $5 \%$ & 0,44 & 51877 \\
\hline 6 & СПб Реновация & 92826 & 177833 & $3 \%$ & 1,92 & 3432 \\
\hline 7 & СК Дальпитерстрой & 352918 & 59271 & $2 \%$ & 0,17 & 2101 \\
\hline
\end{tabular}

$\mathrm{K}_{\text {результативности }}=\mathrm{S}_{\text {введ }} / \mathrm{S}_{\mathrm{CT}}$,

Где $\mathrm{S}_{\text {введ }}$ - площадь объектов, введенных в эксплуатацию за период; $\mathrm{S}_{\mathrm{cт}}$ - объем текущего строительства на конец периода.

Коэффициент результативности работ строительной компании отображает соотношение введенных в эксплуатацию объектов и строящихся объектов на конец периода (в данном случае на конец 2019 и 2020 гг). Оценка результативности работ производится с ориентировкой на условие, что чем ближе коэффициент результативности к единице, тем выше эффективность и быстрота возведения строительных объектов. Превышение объемов сданных объектов относительно объемов текущего строительства (т.е. когда $\mathrm{K}_{\text {результативности }}>1$ ) говорит о снижении активности застройщика на рынке строительства, обусловленное отсутствием проектов и финансирования. В данном случае возникает риск банкротства застройщика.

В связи с тем, что доля, занимаемая компанией на рынке может изменяться в зависимости от критерия, по которому проводилось ранжирование (т.е. в зависимости от объемов сданных объектов и текущего строительства), размер доли компании на рынке застройщиков был определен, как среднее значение долей, занимаемых той или иной компанией на рынке застройщиков, определяемых по данным критериям.

Карта стратегических групп составляется в соответствии со следующими условиями:

1) по горизонтальной оси $X$ отражается доля, занимаемая организацией на рынке застройщиков Санкт-Петербурга;

2) по вертикальной оси Y отражается значение рассчитанного ранее коэффициента результативности работ компании-застройщика;

3) размер шара эквивалентен размеру выручки, полученной компанией-застройщиком за анализируемы период [2].

Отметим, что при составлении карт стратегических групп Glorax Development была исключена, т.к. данных о выручке компании нет в открытом доступе. На основании выявленных данных построим карту стратегических групп отрасли «строительство», которая способ- 
на отразить примерное положение АО «Эталон ЛенСпецСМУ» на рынке среди конкурентов в 2019 (см. рисунок 1) и 2020 гг. (см. рисунок 2).

Ориентируясь на представленную выше карту стратегических связей, можно сделать вывод о том, что лидерами по результативности работ, за рассматриваемый период являются компании «СК Дальпитерстрой» и «СПб Реновация». Копании с наибольшей занимаемой долей рынка: «Setl Group», «ЛСР» имеют меньшую результативность выполнения проектов по возведению объектов недвижимости (это обусловлено наличием отсрочек введения объектов недвижимости в эксплуатацию), вероятно большая доля на рынке обеспечивает также и больший объем выручки данных компаний.

Обратим внимание на положение Группы «ЦДС»: компания занимает не большую долю рынка застройщиков, имеет низкий процент результативности, но тем не менее имеет наибольшую выручку в 2019 году. Данный факт объясняется спецификой отрасли. Во-первых, особенностью учета и признания выручки строительных компаний (как было установлено в части анализа нормативно-правового регулирования отрасли, выручка признается после заключения актов о передаче прав собственности на объект недвижимости), т.е. вероятно, данный застройщик, имея пониженную результативность работ и периодические сдвиги в датах сдачи объектов, признал выручку по ряду договоров позже. Во-вторых, данное положение компании на карте стратегических групп может быть свя- зано с повышенным уровнем цен на недвижимость у данного застройщика.

Заметим, что такие компании, как «СК Дальпитерстрой», «Группа Эталон», «СПб Реновация» занимают примерно равную долю рынка, следовательно, в этой стратегической группе может существовать высокий уровень конкуренции. Но, анализируемая компания «Эталон ЛенСпецСМУ» в сравнении с конкурентами «СК Дальпитерстрой» и «Лидер групп» имеет не такой высокий коэффициент результативности, что в некоторой степени может оказать влияние на дальнейшее положение компании на рынке.

Далее рассмотрим положение компаний в отрасли на конец 2020 года. И произведем сравнение с 2019 годом (см. рисунок 2).

Так, карта стратегических связей за 2020 год отразила следующие изменения:

1) Рост доли занимаемого рынка компаниями: «Setl Group», «ЛСР», «Эталон». Положение остальных компаний, относительно процента занимаемого рынка не изменилось.

2) Снижение коэффициентов результативности работ у большинства строительных компаний. Исключение: «СПб Реновация» - имеет коэффициент результативности 1,92 , что связано с сокращением текущих проектов строительства объектов недвижимости.

3) Рост результативности у «ЦДС», что сделало данную компанию ключевым конкурентом в рамках сегмента компании «Эталон».

4) Сокращение результативности «СК Дальпитерстрой», обусловленное снижением коли-

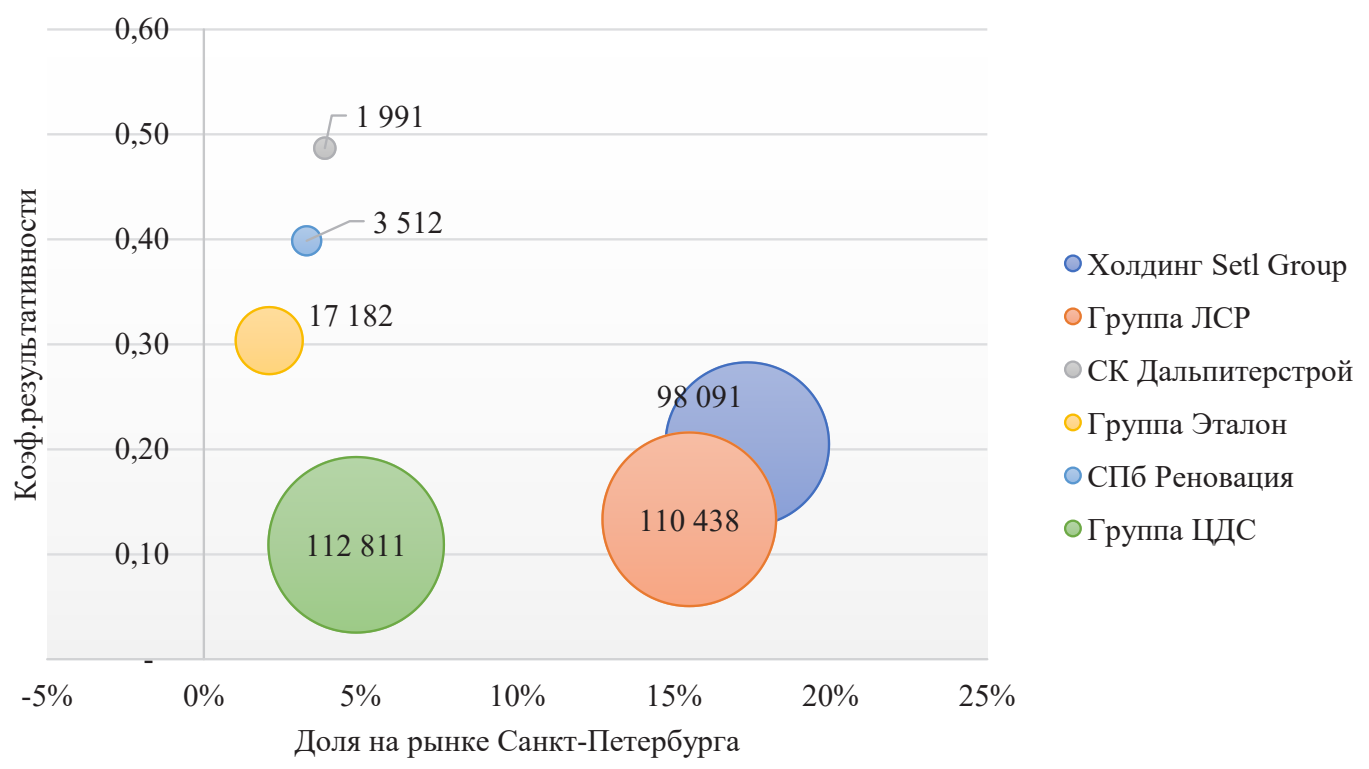

Рисунок 1. Карта стратегических групп конкурентов АО «Эталон ЛенСпецСМУ» по состоянию на конец 2019 года. 


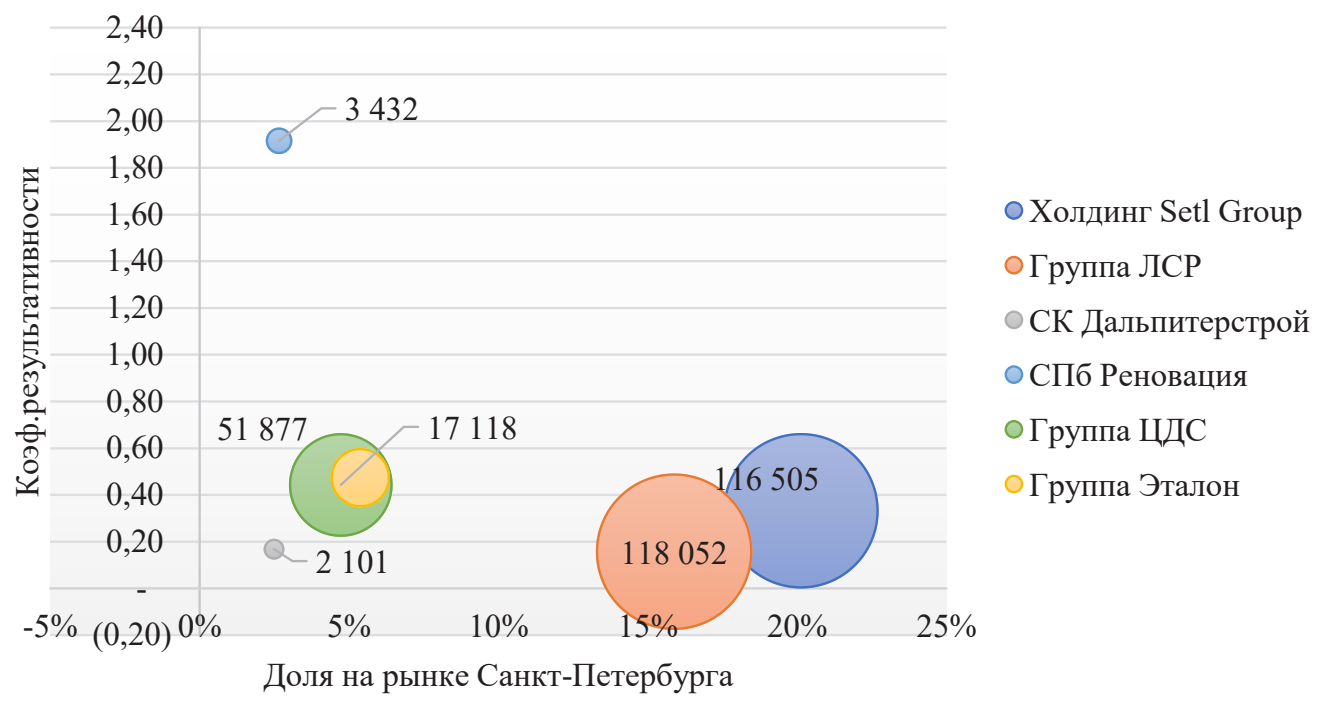

Рисунок 2. Карта стратегических групп конкурентов АО «Эталон ЛенСпецСМУ» по состоянию на конец 2020 года.

чества сданных объектов на конец 2020 года, не стоит исключать, что данная динамика является результатом введения карантинных мер в связи с пандемией COVID-19, что стало результатом временной приостановки строительных работ во втором квартале 2020 года.

В совокупности можно заметить, что отрасль статична: имеется ряд ключевых «игроков», составляющих конкуренцию друг другу, новых крупных застройщиков за рассматриваемый период не возникло. Увеличение занимаемых долей на рынке строительства является следствием естественного функционирования компаний в данной отрасли. Напомним: распределение долей рынка производилось на основании данных о непосредственном функционировании компаний на рынке, а именно на основании наличия текущего строительства и объема сданных объектов в конкретном году. Кроме того, данные изменения на рынке застройщиков также выступают следствием роста количества сделок слияния и поглощения в результате высокой кредитной нагрузки на компании отрасли. Мелким застройщикам недостаточно финансирования для реализации проектов (в силу, например, малоизвестности и как следствие, недоверия со стороны инвесторов и потенциальных покупателей) из-за чего они прибегают к переговорам с более крупными представителями отрасли и как следствие, банкротятся. Примером подобной ситуации выступает история исключенного ранее из выборки застройщика «Glorax Development».
Известно, что компания не смогла обеспечить реализацию проекта Ligovsky City, и прибегла к финансированию со стороны ПАО «ПИК».

Тем не менее компания «Эталон ЛенСпецСМУ» имеет хорошие перспективы развития, известно, что в 2019 году произошло слияние ГК «Эталон» и «Лидер-Инвест» (Эталон выкупили 51\% акций Лидер-Инвеста), что в долгосрочной перспективе позволит Эталону расширить спектр своей деятельности (за счет дополнительных средств от «Лидер-Инвест») и укрепить свои позиции на строительном рынке и составить конкуренцию более крупным компаниям в лице «ЛСР» и «Setl Group». Кроме того, положение данной компании относительно показателей карты стратегических связей не сильно изменилось, что говорит о наличии определенного уровня устойчивости к изменениям во внешней среде (например, ограничения COVID-19 не сказались на величине коэффициента результативности строительных работ).

В дополнение к представленным выше отраслевым особенностям, а также упомянутым ранее потенциальным факторам макросреды (объективным и информационным), необходимо отметить следующую гипотезу: ввиду специфики формирования финансового результата компаний строительной отрасли, обозначим две ключевые группы внешнего воздействия: инвесторы (заказчики) и потребители. Заметим, что в данном случае государство не упоминается, т.к. в силу специфичности его воздействия (законо- 
дательно) оно имеет превалирующий вес над остальными факторами внешней среды, т.е. под воздействие нормативно-правовых актов попадают не только застройщики, но также заказчики и физические лица (потребители, дольщики). В силу развития бизнеса, появления и развития тенденций консолидации отрасли, сопровождающееся укрупнением и усилением влияния нескольких компаний, занимающих наибольшую долю в отрасли, потенциальным инвесторам и покупателям недвижимости сложнее принять решение о вложении средств в проект того или иного застройщика только на основании его объемов, скорости возведения и сдачи объектов недвижимости. И отметим, что данный факт сопровождается постоянным ростом применяемости информационных (в т.ч. маркетинговых) технологий. В соответствие с этим формируется фактор «репутации» бренда застройщика. Потенциальный потребитель или инвестор перед тем, как вложить свои средства, производит некий анализ репутации того или иного застройщика, ориентируясь на информацию, представленную в сети Интернет. На основании этого можно предположить, что тональность (уровень позитивности или негативности) информационного фона вокруг бренда строительной компании влияет на объемы поступаемых от реализации работ и услуг средств (то есть на ее Выручку или Кредиторскую задолженность).

Данный факт формирует необходимость выделения такого этапа анализа, как «подробная оценка тональной компоненты» бренда «Эталон ЛенСпецСМУ» и ключевых ее конкурентов.

На данном этапе развития цифровых технологий, любая компания почти каждой отрасли подвержена влиянию информационной среды. Строительные компании не исключение. В связи с этим имеют место такие факторы, как «количество запросов» в поисковых системах Google, Яндекс и иных. Зачастую такие запросы вводятся целевой аудиторией компании. Прежде чем приобрести жилую недвижимость, человек, потенциальный потребитель, проводит поверхностный анализ рынка недвижимости, выставляемой на продажу. Анализ может осуществляться через ввод тех или иных запросов в поиске, а затем при помощи наиболее релевантных сайтов в выдаче осуществляется сбор информации о средней стоимости, площади, местоположении и, главное, оценка общественного мнения (комментариев) о том или ином жилье. Кроме того, в данном случае, мнение о жилье/новостройке в сознании потребителя эквивалентно мнению о компании-застройщике. На основании этого можно провести оценку востребованности строительной компании на рынке жилой недвижимости. Данный фактор информационной среды хорошо дополняется оценкой тональности отзывов о застройщике на специализированных форумах.

Анализ тональности текста - это класс методов контент-анализа в компьютерной лингвистике, предназначенный для автоматизированного определения в текстах эмоционально окрашенной лексики и эмоциональной оценки авторов (мнений) по отношению к объектам, речь о которых идёт в тексте. Тональность - это эмоциональное отношение автора высказывания к некоторому объекту (объекту реального мира, событию, процессу или их свойствам/атрибутам), выраженное в тексте. Эмоциональная составляющая, выраженная на уровне лексемы или коммуникативного фрагмента, называется лексической тональностью (или лексическим сентиментом). Тональность всего текста в целом можно определить как функцию (в простейшем случае сумму) лексических тональностей составляющих его единиц (предложений) и правил их сочетания. При провидении анализа новостного фона также может быть применена токенизация,- разбиение текста на составляющие, которые в последствии могут быть квантифицированы и подвержены более точному анализу [3].

Таким образом, элементы информационной среды можно дифференцировать на содержательно-тематическую и тональную компоненту. И на основании этого оценка информационной среды вокруг бренда строительной компании подразумевает следующие этапы анализа:

1) Оценка общей заинтересованности индивидуумов в приобретении объекта недвижимости в рамках конкретного субъекта Российской Федерации.

2) Квантификация уровня заинтересованности индивидуумов в конкретном застройщике.

3) Оценка тональной компоненты информационного фона вокруг конкретного застройщика.

4) Анализ и сопоставление результатов оценки информационного фона с конкурентами компании. 
Этап 1. Оценка общей заинтересованности индивидуумов в приобретении объекта недвижимости в рамках Санкт-Петербурга. Так, ценность анализа заключается в проведении оценки комплексного уровня заинтересованности потребителя в приобретении объекта недвижимости в Санкт-Петербурге.

Уровень заинтересованности в приобретении жилья в Санкт-Петербурге отражается в количестве запросов пользователей по релевантным данной тематике тегам. Дальнейший анализ будет проведен на основании статистики запросов пользователей поисковой системы Google. Для целей сбора данных для проведения дальнейшего анализа применяется официальный сервис от Google по сбору статистики поисковых запросов и отслеживанию тенденций в обществе «Google Trends». Анализ запросов на тему приобретения недвижимости в СанктПетербурге (по России), показал, что в ходе изучения жилищного вопроса пользователи чаще всего использовали тег «купить квартиру спб». В таблице 4 представлена выгрузка статистики по количеству запросов по данному тегу за 20172020 гг, Для удобства динамика уровня заинтересованности россиян в приобретении квартир в Санкт-Петербурге отражена на графике рисунка 3.

Таким образом, за период с 2016 по 2020 гг интерес пользователей в приобретении жилья в Санкт-Петербурге увеличился более, чем в 2,5 раза, что отразилось на количестве запросов пользователей по тегу «купить квартиру спб». В дополнение в статистике запросов было произведено построение линии тренда на два периода вперед (2021-2022 гг), что подтвердило наличие тенденции роста показателя заинтересованности.

Этап 2. Оценка уровня заинтересованности индивидуумов в конкретном застройщике. После того, как пользователь провел поверхностный анализ рынка квартир в Санкт-Петербурге у него сформировалось первичное представление о рынке застройщиков в данном регионе. Далее пользователь начинает анализировать наиболее релевантных его предпочтениям (по цене, району расположения объекта недвижимости, класса объекта недвижимости и иных) застройщиков. Анализ информации о застройщике может производиться путем осуществления поиска по тегу с наименованием бренда застройщика. Например «ЛенСпецСМУ».

Таблица 4. Статистика поисковых запросов по тегу «купить квартиру СПб» за 2017-2020гг

\begin{tabular}{|c|c|c|c|c|c|c|c|}
\hline \multirow{2}{*}{ год } & \multicolumn{4}{|c|}{ Квартал } & \multirow{2}{*}{ Итого за год } & \multicolumn{2}{|c|}{ Прирост за год } \\
\hline & 1 & 2 & 3 & 4 & & кол-во запросов & $\% \%$ \\
\hline 2017 & 595 & 573 & 717 & 713 & 2598 & 1340 & $106,5 \%$ \\
\hline 2018 & 667 & 604 & 848 & 801 & 2920 & 322 & $12,4 \%$ \\
\hline 2019 & 830 & 622 & 865 & 811 & 3128 & 208 & $7,1 \%$ \\
\hline 2020 & 741 & 665 & 981 & 936 & 3323 & 195 & $6,2 \%$ \\
\hline
\end{tabular}

Динамика уровня заинтересованности

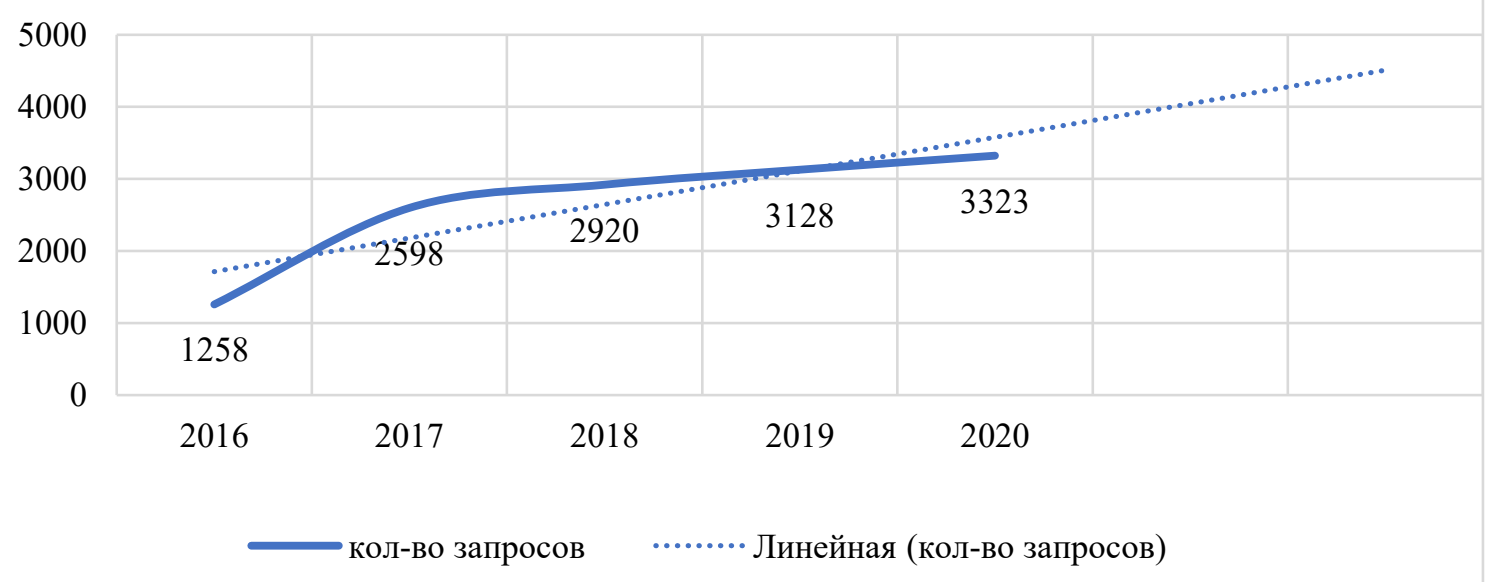

Рисунок 3. Динамика уровня заинтересованности россиян в приобретении жилья в Санкт-Петербурге 
На основании этого был произведен сбор статистики по запросу «ЛенСпецСМУ» (см. таблицу 5 и рисунок 4). Для целей исследования уровня заинтересованности был разработан специальный коэффициент $-\mathrm{K}_{3}$.

$\mathrm{K}_{3}=($ кол-во запросов по тегу «Имя бренда застройщика») / (кол-во запросов по тегу «Купить квартиру СПб»)

Коэффициент заинтересованности отражает долю запросов пользователей по наименованию бренда компании-застройщика в общем количестве запросов по тегу «Купить квартиру СПб». Оценка по данному критерию производится от 0 до 1, превышение величины коэффициента еди- ницы может быть следствием статистической неточности, обусловленной, например, попаданием результатов, относящихся к другому региону. Результаты расчета коэффициента заинтересованности представлены в таблице 6.

Статистика запросов по наименованию бренда «ЛенСпецСМУ» показала снижение количества поисковых запросов в 2019 году на $24 \%$, а в 2020 году на 14\%. Что также нашло отражение в динамике коэффициента заинтересованности (см. таблицу 6)

Этап 3. Оценка тональной компоненты информационного фона вокруг конкретного застройщика. В ходе изучения данных о компании-застройщике непосредственного покупателя в первую очередь интересует качество

Таблица 5. Статистика поисковых запросов по тегу «ЛенСпецСМУ» за 2017-2020гг

\begin{tabular}{|c|c|c|c|c|c|c|c|}
\hline \multirow{2}{*}{ год } & \multicolumn{4}{|c|}{ Квартал } & \multirow{2}{*}{ Итого за год } & \multicolumn{2}{|c|}{ Прирост за год } \\
\hline & 1 & 2 & 3 & 4 & & кол-во запросов & $\% \%$ \\
\hline 2017 & 176 & 184 & 220 & 204 & 784 & -101 & $-11,4 \%$ \\
\hline 2018 & 238 & 170 & 218 & 183 & 809 & 25 & $3,2 \%$ \\
\hline 2019 & 157 & 159 & 149 & 147 & 612 & -197 & $-24,4 \%$ \\
\hline 2020 & 114 & 130 & 170 & 113 & 527 & -85 & $-13,9 \%$ \\
\hline
\end{tabular}

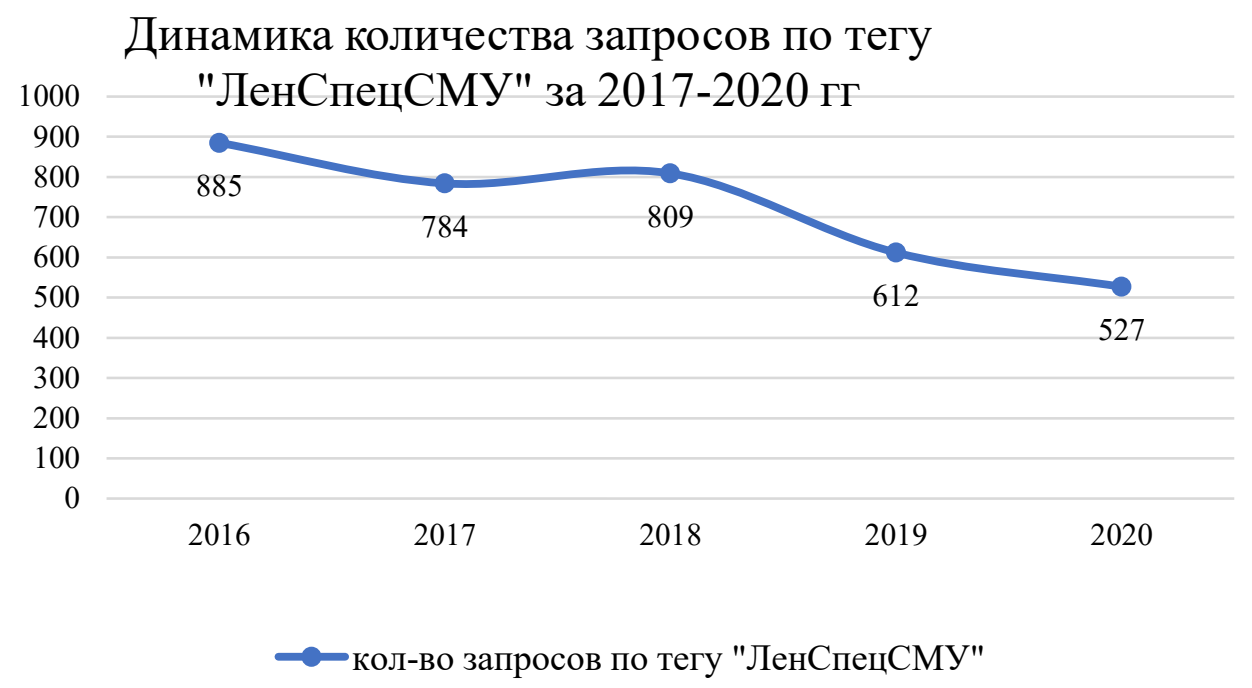

Рисунок 4. Динамика количества запросов по тегу «ЛенСпецСМУ» за 2017-2020 гг

Таблица 6. Коэффициент заинтересованности потребителя в бренде «ЛенСпецСМУ» за 2017-2020 гг

\begin{tabular}{|l|c|}
\hline Год & Коэф. заинтересованности \\
\hline 2016 & 0,70 \\
\hline 2017 & 0,30 \\
\hline 2018 & 0,28 \\
\hline 2019 & 0,20 \\
\hline 2020 & 0,16 \\
\hline
\end{tabular}


приобретаемого объекта недвижимости. В данном случае подключается механизм «сарафанного радио», но в рамках информационной среды. Действия механизма выражается в отзывах о застройщике на тематических форумах. Соотношение позитивности и негативности отзывов о строительной компании влияет на формирование «портрета» компании в голове у потенциального потребителя (или инвестора), что в последствие влияет на принятие решения о вложении средств в тот или иной проект компании.

Таким образом, тональность информационного фона может использоваться в наборе предполагаемых стратегических факторов компании. В силу данного утверждения имеет место гипотеза о воздействии уровня позитивности тона информационного фона вокруг бренда застройщика на формирование его финансового результата или кредиторской задолженности (ранее в ходе анализа внутренней среды компании, а также нормативно-правового регулирования строительной отрасли было выявлено, что средства инвесторов и покупателей недвижимости (дольщиков, например) в первую очередь отражаются в краткосрочной кредиторской задолженности, а далее после подписания актов приемки-передачи прав на объект недвижимости производится признание выручки на сумму переданных объектов недвижимости, что делает показатель «Выручка» менее релевантным для проведения оценки воздействия информационного фона на сумму поступаемых в компанию средств).

В соответствии с обозначенной гипотезой необходимо проведение оценки тональности отзывов о застройщике «Эталон ЛенСпецСМУ».
Для реализации данной цели был определен наиболее релевантный (на основании количества отзывов о застройщике) сайт с отзывами о застройщиках Санкт-Петербурга https://novostroy. spb.ru/. Так, поиск отзывов о застройщике «Эталон ЛенСпецСМУ» показал 209 отзывов разного объема и содержания, за временной промежуток с 2011 по 2020 год включительно, при этом данные на сайте не статичны, то есть количество отзывов может изменяться. Для целей автоматизации процесса формирования совокупности токенов содержательно-тематической компоненты информационной среды использовался язык программирования Python 3. Алгоритм, сбора и анализа Dataframe приведен на рисунке 5.

Результирующим показателем алгоритма анализа информационного фона вокруг компании выступает Коэффициент тональности информационной среды $-\mathrm{K}_{\text {тон }}$.

$$
\mathrm{K}_{\mathrm{TOH}}=\mathrm{K}_{\mathrm{pos}} / \mathrm{K}_{\text {neg, }} \text {, }
$$

Где $\mathrm{K}_{\mathrm{pos}}$ - коэффициент уровня позитивности тона набора лексем; $\mathrm{K}_{n e g}-$ коэффициент уровня негативности тона набора лексем.

Оценка тональности с использованием данного коэффициента производится при соблюдении следующей закономерности: чем выше величина коэффициента тональности, тем выше привлекательность бренда застройщика для целевой аудитории.

Далее произведем укрупненное рассмотрение этапов реализации автоматизированного алгоритма сбора, квантификации и последующей оценка характеристики информационной

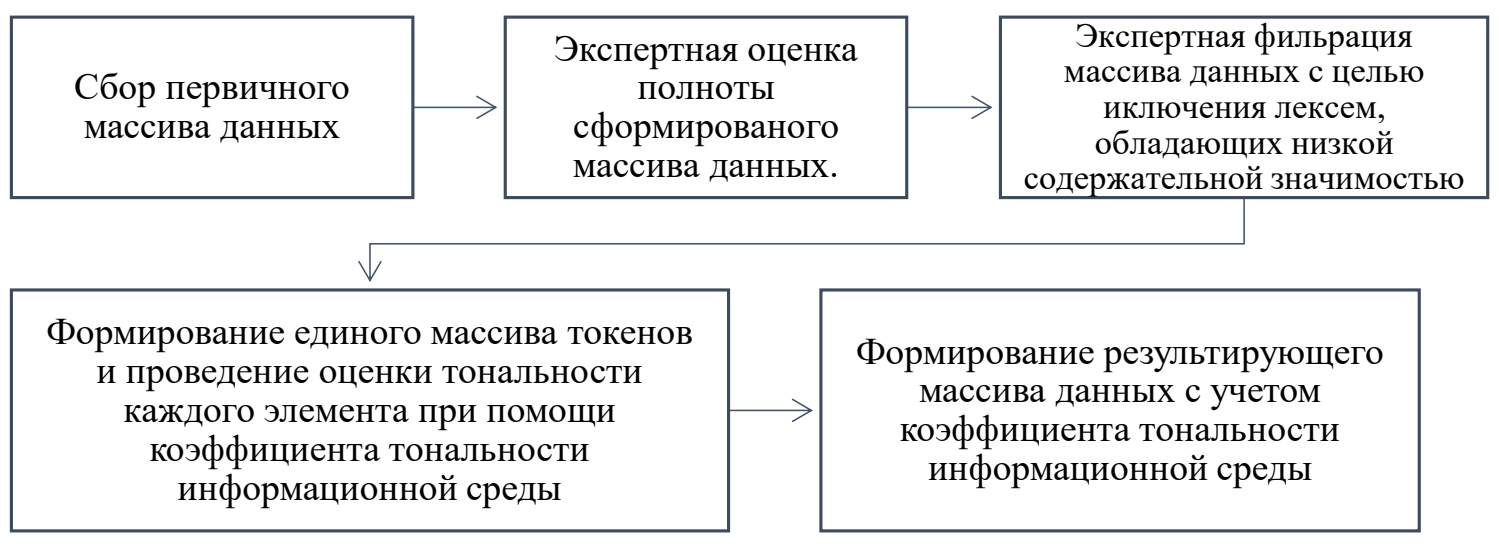

Рисунок 5. Алгоритм формирования совокупности токенов содержательно-тематической компоненты информационной среды и оценки тональности информационной среды специализированного сайта с отзывами о застройщике [4] 
среды строительной компании. Отметим, что данный алгоритм применим в рамках конкретного, обозначенного ранее портала отзывов о застройщиках Санкт-Петербурга. В силу этого алгоритм может быть применен для любого застройщика (строительной компании), отзывы о котором представлены на данном сайте.

Этап 1. Автоматизированный сбор массива данных о компании-застройщике. Парсинг сайта с отзывами о застройщике. В рамках данного этапа производится автоматизированный сбор массива с отзывами о строительной компании. Для осуществления быстрого автоматизированного сбора массива данных было предложено использовать библиотеку Requests. Инструментарий данной библиотеки предназначен для легкого и с минимальным количеством кода взаимодействия с веб-приложениями (с сайтами). Еще одним важным инструментом сбора данных является библиотека BeautifulSoup4, т.к. применение функций данной библиотеки, в контексте разработанного в данной работе кода, позволяет производить автоматизированную выгрузку текстовых компонент с заданного сайта.

Далее возникает необходимость выгрузки массива с отзывами о застройщике, полученного в результате парсинга заданного сайта. Для реализации данной задачи применяется библиотека Pandas, позволяющая сохранить имеющийся массив в формате Excel.

Этап 2. Токенизация сформированного массива с отзывами о строительной компании и оценка тональности отзывов. Для осуществления автоматизированной и объективной оценки тона отобранных компонент (отзывов) применяется инструментарий библиотеки Dostoevsky, позволяющий произвести автоматизированную фильтрацию массива текстовых данных на несколько категорий: позитивную, негативную, нейтральную.

В целях данного исследования производится оценка тональности отзывов о строительной компании с применением коэффициента тональности (см. формулу 3). Сперва производится поэтапный анализ каждого отзыва и определяется уровень его позитивности и негативности, эти данные сохраняются в отдельные одноименные списки. Далее задается формула расчета коэффициента тональности отзыва. Результатом является сформированный массив данных (отзывов) о компании-застройщике, с вычисленной величиной коэффициента тональности.

В результате квантификации и последующей выгрузки данных о тональности информационного фона вокруг АО «Эталон ЛенСпецСМУ», для целей анализа применяется усредненный коэффициент тональности за период с 2017 по 2020 гг. Динамика коэффициента представлена на рисунке 6.

Далее произведем проверку гипотезы о влиянии позитивности информационного фона вокруг бренда компании на изменение кредиторской задолженности предприятия. Реализуем данную проверку с использованием пакета анализа данных MS Excel, а именно Регрессионного анализа. Для этого произведем выгрузку данных о коэффициенте «позитивности» $\mathrm{K}_{\text {pos. }}$ В резуль-

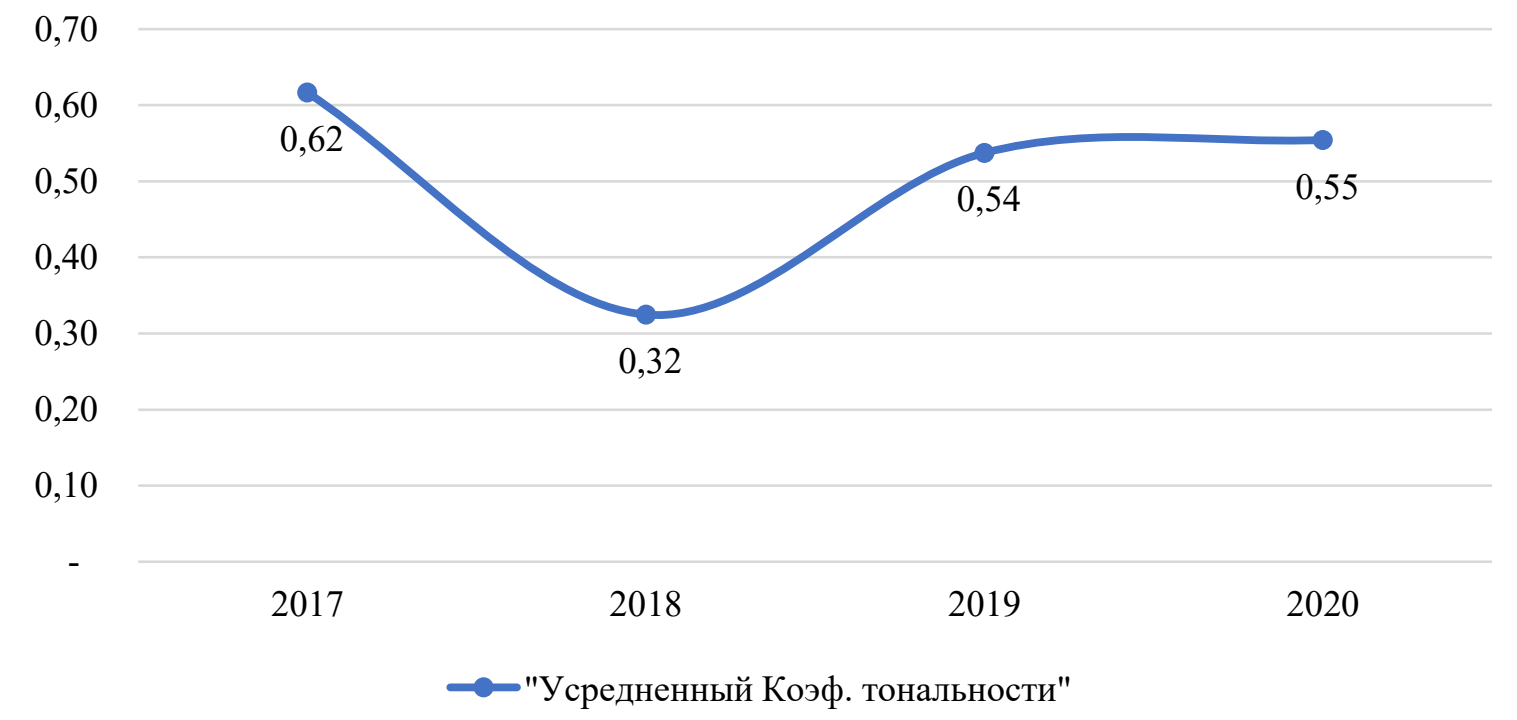

Рисунок 6. Динамика тональности информационного фона вокруг АО «Эталон ЛенСпецСМУ» за период 2017-2020 гг. 
тате получив следующий набор данных (см. таблицу 7) проведем анализ регрессии (см. рисунок 7). Величина стандартизированной ошибки $14 \%$, что говорит о низком качестве данной модели и отсутствии зависимости между анализируемыми факторами.

Выявленное в результате регрессионного анализа отсутствие зависимости между изменениями тональной компоненты и размеров кредиторской задолженности объясняется спецификой анализируемой отрасли. Как было отмечено ранее строительная отрасль, как и ее продукт, имеют довольно статичный характер, что в том числе обусловлено длительностью сроков создания нового продукта, его реализации и т.д. Процесс приобретения недвижимости довольно длителен, в связи с тем, что потребителю необходимо пройти несколько этапов проверки застройщика на соответствие определенным критериям. То есть вложение средств редко обретают спонтанный характер. Иными словами, отсутствие зависимости в контексте данной гипотезы объясняется наличием временного лага.

Так же стоит иметь в виду, что потенциальный клиент или заказчик в ходе проверки соответствия компании-застройщика его субъективным требованиям, ориентируется на отзывы предыдущих лет и проектов. То есть, снижение коэффициента тональности информационной компоненты в 2020 году не означает резкое снижение активности поступления средств в этом же году, т.к. в 2019 году оценка тональности была значительно выше и потенциальный инвестор и/или потребитель может посчитать отзывы за 2019 год более весомыми, относительно 2020 и затем, вложить свои средства в проект 2021 года.

Таким образом, фактор тональности информационного фона может выступать в качестве одного из стратегических и имеет место при формировании диджитал-ориентированной стратегии, учитывающей наличие «накопительного» характера тональности информационного

\begin{tabular}{|c|c|}
\hline \multicolumn{2}{|l|}{ SUMMARY OUTPUT } \\
\hline \multicolumn{2}{|c|}{ Regression Statistics } \\
\hline Multiple R & 0,38 \\
\hline R Square & 0,14 \\
\hline Adjusted R Square & 0,08 \\
\hline Standard Error & 3040449,87 \\
\hline Observations & 16 \\
\hline
\end{tabular}

Рисунок 7. Результат проведения регрессионного анализа.

Таблица 7. Данные для осуществления проверки наличия связи между Кредиторской задолженностью и Kpos

\begin{tabular}{|c|c|c|}
\hline год & Краткосрочная К3 & Коs \\
\hline \multirow{4}{*}{2017} & 20575545 & 0,15 \\
\cline { 2 - 3 } & 16854329 & 0,38 \\
\cline { 2 - 3 } & 21193432 & 0,10 \\
\cline { 2 - 3 } & 23486780 & 0,06 \\
\hline \multirow{4}{*}{2018} & 25593811 & 0,09 \\
\cline { 2 - 3 } & 22918703 & 0,07 \\
\cline { 2 - 3 } & 23922209 & 0,04 \\
\hline \multirow{4}{*}{2019} & 25552614 & 0,10 \\
\cline { 2 - 3 } & 27527687 & 0,11 \\
\cline { 2 - 3 } & 26255644 & 0,09 \\
\cline { 2 - 3 } & 25074901 & 0,14 \\
\hline \multirow{4}{*}{2020} & 26988830 & 0,15 \\
\cline { 2 - 3 } & 26306652 & 0,14 \\
\cline { 2 - 3 } & 25704209 & 0,27 \\
\cline { 2 - 3 } & 22945653 & 0,14 \\
\hline \multirow{4}{*}{} & 17758577 & 0,11 \\
\hline
\end{tabular}


фона. Для подтверждения влияние тональности информационного фона на финансовый результат компании необходимо проведение более длительного исследования.

Этап 4. Анализ и сопоставление результатов оценки информационного фона с конкурентами компании. В рамках данного этапа анализа факторов информационной среды подразумевается проведение комплексного анализа положения компании АО «Эталон ЛенСпецСМУ» на рынке застройщиков в сопоставлении с ключевыми конкурентами в лице: Холдинга «Setl Group», Группы ЛСР и Группы ЦДС. Результаты анализа удобнее представить в виде трансформированной карты стратегических групп, где по оси-Х отражается величина коэффициента тональности, по оси-Ү уровень заинтересованности целевой аудитории в бренде застройщика. Размер кругов соответствует размеру выручки компании (см. рисунок 8).

Таким образом, по карте стратегических групп видно, что все рассматриваемые компании осуществляют свою деятельность в пределах одного тонального сегмента. Кроме того, компании имеют схожий уровень заинтересованности/актуальности у потребителя. Данный факт говорит о высоком уровне конкуренции среди данной группы застройщиков СанктПетербурга. Далее произведем расчет всех упомянутых ранее стратегических показателей для ключевых конкурентов АО «Эталон ЛенСпецСМУ» (см. таблицу 8).

Итак, произведем анализ положения АО «Эталон ЛенСпецСМУ» по данным карты комплексного сравнения стратегических показателей (см. рисунок 9). Отметим, что в ходе анализа показателей будет сформирован рейтинг компаний-застройщиков по характеристикам каждого из показателей в отдельности. Далее будет произведено составление комплексного, усредненного рейтинга компаний.

1) Коэффициент тональности информационной среды вокруг бренда застройщика.

Ранжирование ключевых игроков рынка застройщиков Санкт-Петербурга по критерию положительности информационного тона отзывов ( $\left.\mathrm{K}_{\text {тон }}\right)$ показало, что проекты компании ЦДС имеют наиболее высокую признательность

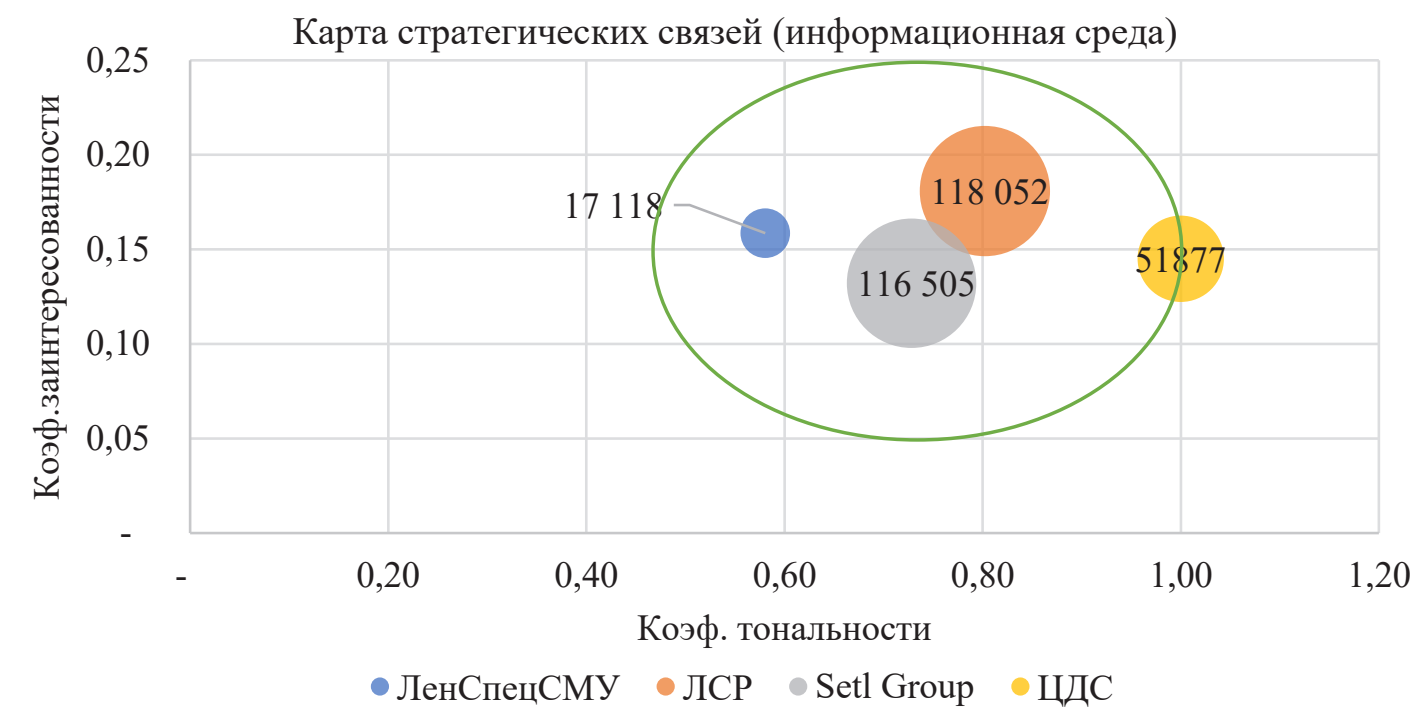

Рисунок 8. Карта стратегических групп на основании данных показателей информационной среды.

Таблица 8. Результаты расчета стратегических показателей

\begin{tabular}{|l|c|c|c|c|}
\hline \multicolumn{1}{|c|}{ Компания } & Коэф. тональности & $\begin{array}{c}\text { Коэф. заинтересо- } \\
\text { ванности }\end{array}$ & Коэф. результ & $\begin{array}{c}\text { Коэф рентаб. } \\
\text { продаж }\end{array}$ \\
\hline ЛенСпецСМУ & 0,58 & 0,16 & 0,47 & 0,48 \\
\hline ЛСР & 0,80 & 0,18 & 0,16 & 0,10 \\
\hline Setl Group & 0,73 & 0,13 & 0,33 & 0,14 \\
\hline ЦДС & 1 & 0,15 & 0,44 & 0,02 \\
\hline
\end{tabular}


у конечного потребителя, т.к. анализ массива отзывов о данном застройщике показал наиболее высокое значение коэффициента тональности информационной среды. Данный факт делает компанию ЦДС лидером в анализируемой категории. Компании ЛСР и Setl Group имеют примерно одинаковую оценку. Эталон ЛенСпецСМУ занимает низшую позицию в рейтинге, в связи с тем, что средняя величина коэффициента тональности имеет значение 0,58 единиц, то есть, лишь 58\% конечных потребителей считают продукт компании «хорошим» (см. таблицу 9).

2) Коэффициент заинтересованности россиян в бренде застройщика (табл. 10).

В результате ранжирования по критерию заинтересованности россиян в бренде застройщика определено, что наиболее часто пользователи ищут информацию по застройщику «Группа ЛСР». «ЛенСпецСМУ» имеет второе место по заинтересованности пользователей. С другой стороны, если представить результаты ранжирования в виде схемы на рисунке 9, видно, что все рассматриваемые застройщики имеют схожий уровень «публичности».

3) Коэффициент результативности строительных работ (табл. 11).
По состоянию результативности работ на конец 2020 года АО «ЭТалонЛенСпецСМУ» имеет наиболее высокий показатель, что делает ее лидером при ранжировании по данному критерию. Группа ЦДС, являющаяся прямым конкурентом «ЛенСпецСМУ» (по данным предварительного анализа отрасли, см. рисунок 8) имеет приближенные к ЛенСпецСМУ показатели результативности. Примем во внимание результаты сравнения по данному критерию, представленные на рисунке 9: зеленым кругом обозначены три компании, оперирующие в относительно равном сегменте. То есть, прямыми конкурентами АО «Эталон ЛенСпецСМУ» по результативности строительных работ являются компании «ЦДС» и «Setl Group». Примечательно, что «ЛСР», являющаяся прямым конкурентом «Setl Group», имеет наименьшее значение коэффициента результативности на конец 2020 года, что при дальнейшем сохранении подобной тенденции может привезти к ослаблению ее конкурентоспособности.

4) Коэффициент рентабельности продаж компаний-застройщиков (табл. 12).

Оценка рентабельности продаж показала, что АО «Эталон ЛенСпецСМУ» имеет наиболь-

Таблица 9. Ранжирование по критерию положительности информационного тона отзывов о застройщике

\begin{tabular}{|c|l|c|}
\hline Место & \multicolumn{1}{|c|}{ Компания } & К тональности \\
\hline 1 & ЦДС & 1,00 \\
\hline 2 & ЛСР & 0,80 \\
\hline 3 & Setl Group & 0,73 \\
\hline 4 & ЛенСпецСМУ & 0,58 \\
\hline
\end{tabular}

Таблица 10. Ранжирование по критерию заинтересованности россиян в бренде застройщика

\begin{tabular}{|c|l|c|}
\hline Место & \multicolumn{1}{|c|}{ Компания } & Коэф. заинтересованности \\
\hline 1 & ЛСР & 0,18 \\
\hline 2 & ЛенСпецСМУ & 0,16 \\
\hline 3 & ЦДС & 0,15 \\
\hline 4 & Setl Group & 0,13 \\
\hline
\end{tabular}

Таблица 11. Ранжирование по критерию результативности застройщика.

\begin{tabular}{|c|l|c|}
\hline Место & \multicolumn{1}{|c|}{ Компания } & К результативности \\
\hline 1 & ЛенСпецСМУ & 0,47 \\
\hline 2 & ЦДС & 0,44 \\
\hline 3 & Setl Group & 0,33 \\
\hline 4 & ЛСР & 0,16 \\
\hline
\end{tabular}


Таблиц̧а 12. Ранжирование по критерию рентабельности продаж компаний-застройщиков

\begin{tabular}{|c|l|c|}
\hline Место & \multicolumn{1}{|c|}{ Компания } & К рентаб. продаж \\
\hline 1 & ЛенСпецСМУ & 0,48 \\
\hline 2 & Setl Group & 0,14 \\
\hline 3 & ЛСР & 0,10 \\
\hline 4 & ЦДС & 0,02 \\
\hline
\end{tabular}

шую прибыльность от осуществления своей деятельности, что делает ее более привлекательной для инвесторов. Прямой конкурент ЛенСпецСМУ, Группа ЦДС имеет наименьшую рентабельность продаж на конец 2020 года, что является следствием высокой себестоимости реализуемых проектов. Лидеры отрасли (по данным предварительного анализа) Setl Group» и «ЛСР» имеют примерно один уровень рентабельности. На рисунке 9 компании, принадлежащие к одному сегменту доходности обозначены зеленым кругом.

Далее составим комплексный рейтинг застройщиков, с целью понять истинное положение анализируемого предприятия на рынке компаний-застройщиков Санкт-Петербурга (см. таблицу 13).
В результате составления комплексного рейтинга предварительная оценка расположения компаний в отрасли подтвердилась. АО «Эталон ЛенСпецСМУ» и «Группа ЦДС» являются прямыми конкурентами. На основании этого далее необходимо провести анализ показателей, улучшение которых позволило бы АО «Эталон ЛенСпецСМУ» повысить конкурентоспособность и превзойти ЦДС (или как минимум, не позволить «поглотить»). В ходе анализа было выявлено, что ключевым преимуществом ЦДС является высокий уровень позитивности обратной связи от потребителя. С другой стороны, ЛенСпецСМУ имеет незначительный уровень преимущества по показателю результативности строительных работ, что делает этот фактор значимым в ключе конкурентоспособности компании.

Сравнение стратегических показателей компаний-застройщиков

ЛенСпецСМУ $\square$ ЛСР $\square$ Setl Group $\square$ ЦДС

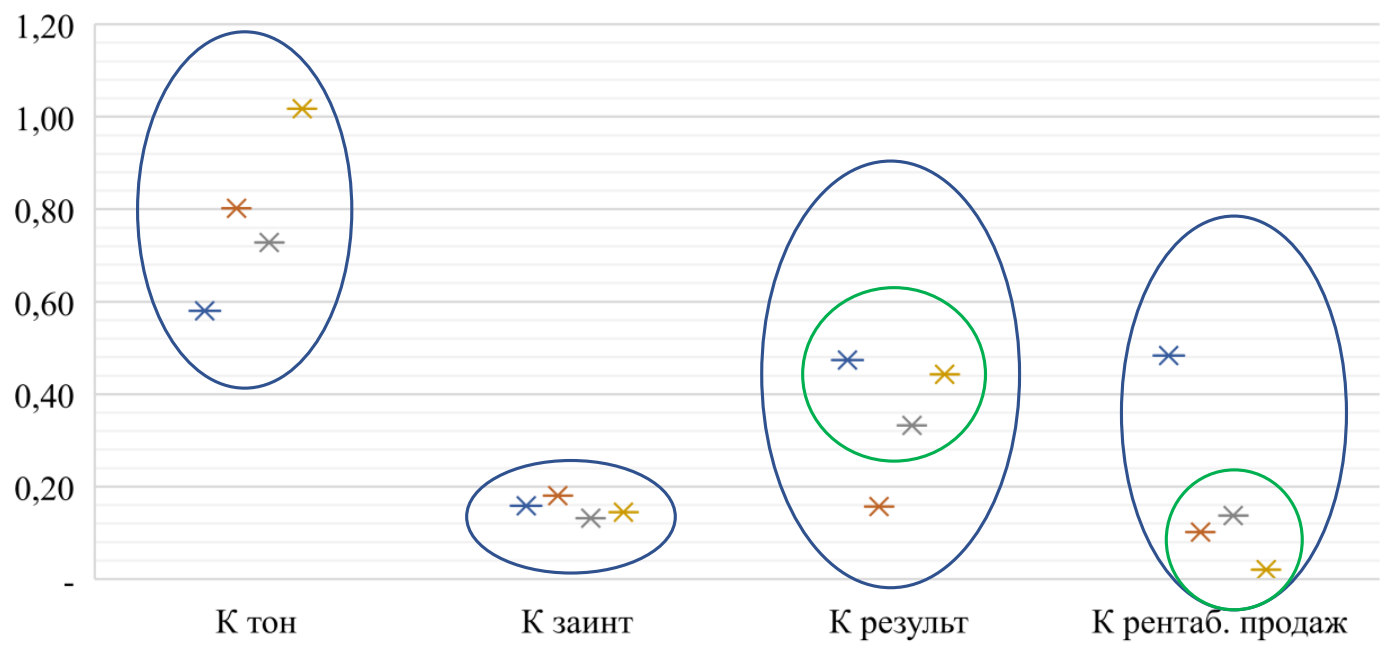

Рисунок 9. Сравнение стратегических показателей компаний-застройщиков

Таблица 13. Рейтинг застройщиков по состоянию на конец 2020 года.

\begin{tabular}{|l|c|c|c|c|c|c|c|}
\hline \multicolumn{1}{|c|}{ Компания } & К тон & К заинт & К результ & К рентаб. & $\begin{array}{c}\text { Доля } \\
\text { рынка }\end{array}$ & Выручка & $\begin{array}{c}\text { Итого } \\
\text { рейтинг }\end{array}$ \\
\hline ЛенСпецСМУ & 4 & 2 & 1 & 1 & 3 & 4 & 3 \\
\hline ЦДС & 1 & 3 & 2 & 4 & 3 & 3 & 3 \\
\hline Setl Group & 2 & 4 & 3 & 2 & 1 & 2 & 2 \\
\hline ЛСР & 3 & 1 & 4 & 3 & 2 & 1 & 2 \\
\hline
\end{tabular}


Как было заявлено ранее, ключевой особенностью данной исследовательской работы является внедрение элементов диджитал (цифровой) среды в стратегию строительной компании АО «Эталон ЛенСпецСМУ».

Стратегия компании подразумевает оценку не только показателей макросреды, но также и квантификацию изменений показателей внутренней среды под воздействием разного рода факторов. Анализ рентабельности показал, что предприятие несмотря на повышенный уровень обязательств, является прибыльным. Примечательно, что высокая рентабельность - это то, что выделяет АО «Эталон ЛенСпецСМУ» на фоне прямых конкурентов (см. рисунок 9) и является ее конкурентным преимуществом. В качестве индикатора эффективности функционирования компании с точки зрения оперативности реализации проектов строительства далее можно использовать динамику значений коэффициента результативности строительных работ, т.к. он отражает соотношение объема сданных объектов и текущего строительства. Как известно оба показателя объема находят прямое отражение в отчетности компании. Так, в силу специфики учета доходов компании, выручка признается лишь после передачи прав собственности на тот или иной объект недвижимости, что осуществимо лишь после полной сдачи объекта в эксплуатацию. Иными словами, на основании особенностей законодательного регулирования строительной деятельности и специфичности учета входящих денежных потоков, коэффициент результативности может считаться отражением определенного уровня инвестиционной привлекательности компании-застройщика, что может быть использовано в качестве стратегического фактора.

В качестве стратегических факторов диджитал-среды может быть использован фактор тональности новостного и общего информационного фона вокруг бренда компании. Как было отмечено ранее, ключевым конкурентом АО «Эталон ЛенСпецСМУ» в рамках информационной среды выступает Группа ЦДС, т.к. на конец 2020 года компании занимают почти равную долю на рынке застройщиков Санкт-Петербурга и имеют относительно один уровень результативности работ (см. рисунок 9 и 2). Уровень заинтересованности потенциальных потребителей в приобретении жилья от конкретного застройщика определяет также некий уровень «массовости» застройщика. Компани ЦДС имеет высокую оценку тональности информационного фона, что в свою очередь делает ее более привлекательной для потенциальных инвесторов(заказчиков) и покупателей недвижимости. Эталон же имеет наиболее низкий уровень тональности информационной среды. Но стоит отметить, что ЦДС за последние несколько лет расширили спектр оказываемых услуг: компания занимается реализацией проектов строительства жилья не только классов «комфорт» и «бизнес», но также и «эконом», что в первую очередь сказывается на уровне «массовости» компании, т.е. расширяет ее целевую аудиторию, а это в свою очередь приводит к росту освещения компании в сети Интернет и сказывается на общем уровне тональности отзывов о данном застройщике.

Динамика данных факторов информационной среды в перспективе способна оказать влияние на общий уровень доходов компании, т.к. в силу особенностей строительной отрасли (длительность реализации проектов, длительность принятия решения потребителем о приобретении жилья) имеет место наличие временной задержки реакции потребителей (или инвесторов) на тональность информации в сети о застройщике. В силу данных обстоятельств разработка диджитал-ориентированной стратегии будет предполагать работу над составлением качественного, наиболее привлекательного для целевой аудитории образа компании.

\section{Библиографический список}

1. Портал «Единый Ресурс Застройщиков» - рейтинг застройщиков URL: https://erzrf.ru/top-zastroyshchikov/ sankt-peterburg?topType $=0 \&$ date $=210101$

2. Портал «Интерфакс», раскрытия отчетности компаний - URL: https://www.e-disclosure.ru/?attempt=1

3. Конников Е.А., Чорная С. А. статья «Особенности формирования стратегического портфеля факторов внешней среды строительной компании» - Журнал «Экономические науки» № 193 декабрь 2020 - URL: https:// ecsn.ru/articles/index/202012

4. Ершова А.В., Родионов Д.Г., Конников Е. А., Конникова О.А. «Системный анализ привлекательности банков для представителей вип-сегмента потребителей в рамках цифровой информационной среды» -[Электронный ресурс] - URL: https://www.elibrary.ru/item.asp?id=44755666 